\title{
Study of the fabric structure influence on the physical-mechanical and technological properties of knitted products
}

\author{
Nozimjon Jurabayev ${ }^{1 *}$, Shakhboz Shogofurov ${ }^{1}$, Kurbonali Kholikov ${ }^{1}$, and Umarjon \\ Meliboev $^{1}$ \\ ${ }^{1}$ Namangan Institute of Engineering and Technology, 160115 Namangan, Uzbekistan
}

\begin{abstract}
Three kinds of knitted fabrics with high shape retention capacity equipment LONG-XING SM 252 (China) 12-grade flat needle loom were produced, their technological characteristics were compared, and graphical records were supplied in this article based on experimental samples of knitted rubber fabric. The developed variants of knitted fabric differ from each other in pattern type, report, shape retention feature and a number of other indicators. Physical and mechanical properties of the obtained samples were determined experimentally on modern equipment installed in the testing laboratory of the Namangan Institute of Engineering Technology.
\end{abstract}

\section{Introduction}

When designing any new knitted fabric or knitted product, the fabric is based on parameters such as loop pitch $\boldsymbol{A}$, loop row height $\boldsymbol{B}$, loop strip length $\boldsymbol{L}$, hygienic, aesthetic and exploitative requirements $[1,2]$.

The surface density and other properties of knitted fabric will depend on these parameters. Knowing that each of these features depends on the performance of the knitted fabric, it is possible to choose the optimal variant of the knitting process. Properties and performance of transverse and longitudinal knitted fabrics with different structure can meet the requirements for technical and upper knitted products in production practice [3].

The nature of the raw material used, the type of fabric and the method of processing are the main factors influencing the performance of any knitted fabric. Knitted fabric can be composed of different fabrics. This condition can change the structure of knitted fabric, thereby affecting its technological and physico-mechanical performance. Its shape retention, air permeability and raw material consumption are important indicators for the consumer in the production of knitted fabrics [4-7]. Technological and physico-mechanical properties of knitted fabric can be determined using the following methods:

1. According to the standard (GOST, OST and technical conditions TSh). When it is not necessary to determine the knitted fabric by calculating the performance (for example, in the calculation of trim, tire, bead details, etc.), or when the technological performance of knitted fabric is calculated using existing formulas, significantly different from the actual

*Corresponding author: jnozimjon@gmail.com 
performance (e.g. new structure in determining the performance of existing or knitted fabric made from fresh raw material) this method can be used. It should be noted that the existing GOST and TSh do not include all fabrics $[8,9]$;

2. Experimental determination. This method is used in the process of scientific work on the creation of new knitted fabrics. In this method, the necessary tools, raw materials, etc. availability is required $[10]$;

3. Calculation method. This method can be used in all cases of design. The sequence of calculation of technological parameters is based on the method adopted for the calculation of the ring strip length $\boldsymbol{L}[11,12]$;

4. Knitted fabric test laboratory method. The test is carried out in this approach by repeating each sample numerous times with laboratory instruments and comparing the findings to the needed GOST Standard and TSh Standard [12].

\section{Materials and Methods}

Table 1. Technological and physical-mechanical parameters of knitted fabrics

\begin{tabular}{|c|c|c|c|c|}
\hline \multirow{2}{*}{\multicolumn{2}{|c|}{ Indicators }} & \multicolumn{3}{|c|}{ Versions } \\
\hline & & \multirow{2}{*}{$\begin{array}{c}\text { I } \\
\text { Polyacrilnitryl } \\
\text { 35tex x2 }\end{array}$} & \multirow{2}{*}{$\begin{array}{c}\text { II } \\
\text { Polyacrilnitryl } \\
\text { 35tex x2 }\end{array}$} & \multirow{2}{*}{$\begin{array}{c}\text { III } \\
\text { Polyacrilnitryl } \\
\text { 35tex } \times 2\end{array}$} \\
\hline \multirow{2}{*}{$\begin{array}{l}\text { Thread type, linear } \\
\text { densities }\end{array}$} & Back side & & & \\
\hline & Front side & $\begin{array}{c}\text { Polyacrilnitryl } \\
\text { 35tex x2 } \\
\end{array}$ & $\begin{array}{c}\text { Polyacrilnitryl } \\
\text { 35tex x2 } \\
\end{array}$ & $\begin{array}{c}\text { Polyacrilnitryl } \\
\text { 35tex x2 } \\
\end{array}$ \\
\hline \multicolumn{2}{|c|}{ ring step $\mathrm{A}(\mathrm{mm})$} & 0.91 & 0.86 & 1.02 \\
\hline \multicolumn{2}{|c|}{ ring row height $\mathrm{B}(\mathrm{mm})$} & 1.31 & 0.94 & 1.39 \\
\hline \multicolumn{2}{|c|}{$\begin{array}{l}\text { Horizontal density } \operatorname{Rg} \text { (number of } \\
\text { rings) }\end{array}$} & 55 & 58 & 49 \\
\hline \multicolumn{2}{|c|}{ Vertical density Rv (number of rings) } & 38 & 53 & 36 \\
\hline \multicolumn{2}{|c|}{ The length of the ring strip L (mm) } & 6.5 & 6.3 & 6.7 \\
\hline \multicolumn{2}{|c|}{ Knitted surface density $\mathrm{Ms}\left(\mathrm{gr} / \mathrm{m}^{2}\right)$} & 425 & 436 & 402 \\
\hline \multicolumn{2}{|c|}{ Knitting thickness T (mm) } & 2.4 & 2.6 & 2.8 \\
\hline \multicolumn{2}{|c|}{ Dimensional density $\delta\left(\mathrm{mg} / \mathrm{cm}^{3}\right)$} & 177 & 167 & 144 \\
\hline \multicolumn{2}{|c|}{ Air permeability $\mathrm{B}\left(\mathrm{cm}^{3} / \mathrm{cm}^{2} \cdot \mathrm{sec}\right)$} & 43.5 & 40.4 & 41.8 \\
\hline \multirow{2}{*}{ Breaking force $\mathrm{P}(\mathrm{H})$} & height & 544 & 543 & 425 \\
\hline & width & 233 & 181 & 169 \\
\hline \multirow{2}{*}{ Stretching to break L (\%) } & height & 56.8 & 29.15 & 39,8 \\
\hline & width & 63.7 & 49.4 & 27,6 \\
\hline \multirow{2}{*}{$\begin{array}{l}\text { Irreversible deformation } \varepsilon_{\mathrm{n}} \\
(\%)\end{array}$} & height & 13.7 & 12.5 & 9,9 \\
\hline & width & 17.8 & 16.8 & 14,9 \\
\hline \multirow{2}{*}{ Back deformation $\varepsilon_{0}(\%)$} & height & 86.3 & 87.5 & 90,1 \\
\hline & width & 82.8 & 83.2 & 85,1 \\
\hline \multirow{2}{*}{ Shrink of fabric K (\%) } & height & 2 & 3 & 4 \\
\hline & width & 5 & 6 & 5 \\
\hline \multicolumn{2}{|c|}{$\begin{array}{c}\text { Friction resistance I } \\
\text { ('000/Circle) }\end{array}$} & 38.3 & 41.1 & 37.8 \\
\hline
\end{tabular}

In order to reduce the consumption of raw materials and expand the range of knitted fabrics, as well as expand the technological capabilities of the flat needle machine LONGXING SM 252 (China), 3 variants of the knitted fabric structure and its weaving method 
were developed. The developed variants of knitted fabric differ from each other in pattern type, report, shape retention feature and a number of other indicators. The experimental method was used to determine technological parameters of knitted fabric in the Namangan Institute of Engineering Technology's knitting production laboratory, and physical and mechanical parameters were determined in the sewing laboratory; the measurement results are listed in Table 1.

As a result of practical research, the texture structure, physical properties and appearance, which characterize the quality indicators of knitwear, were identified. Indicators that characterize the structure of knitted fabric are: surface and volume density, density in width and length (number of loops per unit length), length of loop strand, angle of intersection of loop rows and loop columns, thickness of knitted fabric.Physico-mechanical properties of knitted fabric are air permeability, elongation at break, elongation, reversible and irreversible deformation, abrasion resistance, fabric penetration. A graphic representation of the two-layer knitted fabric produced is shown in Fig. 1.

As a raw material was used polyacrylonitrile yarn with a linear density of 35 tex x 2 .
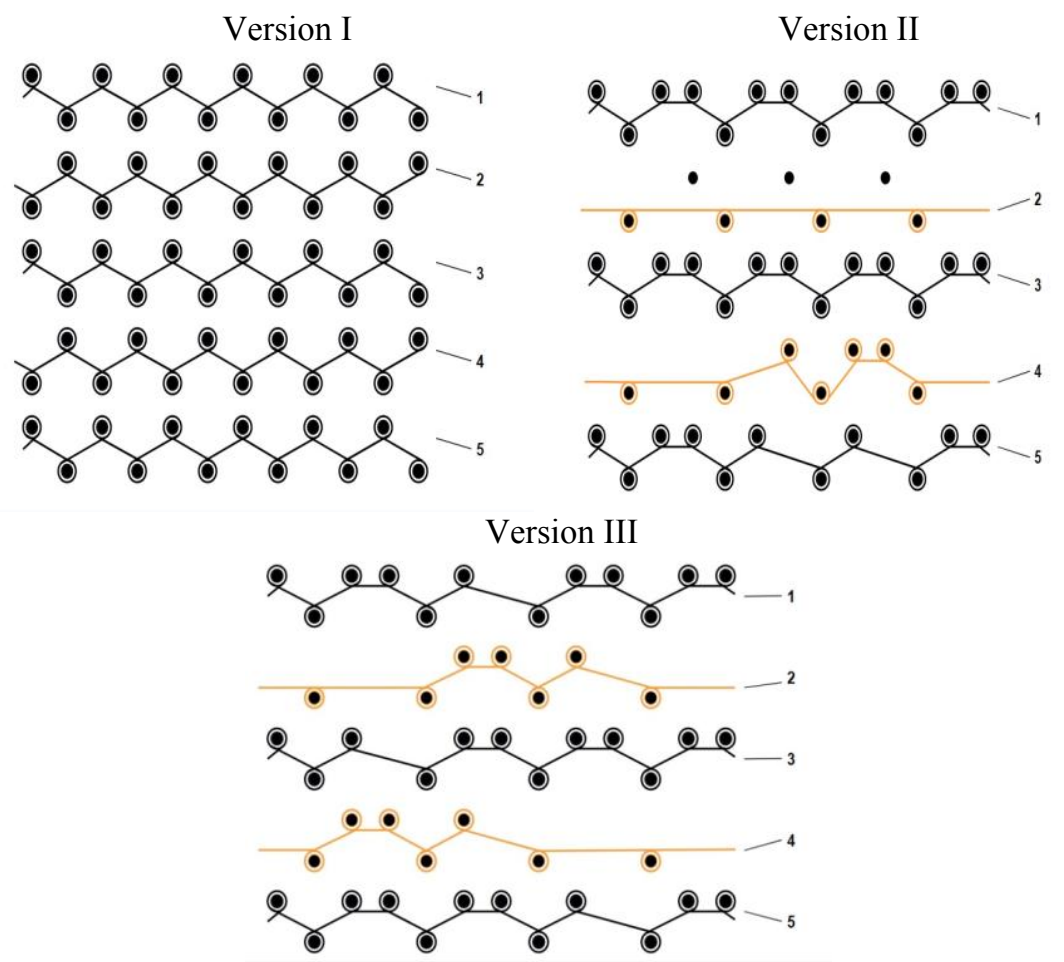

Fig. 1. Graphic notation of knitted fabric

Because the same raw material was used, the structure of the knitwear changed. It was discovered that the volume density index of knitted textiles in all versions was much lower than the basic fabric.

\section{Results and Discussion}

The bulk density of knitted fabric ranged from $177 \mathrm{mg} / \mathrm{cm}^{3}$ to $144 \mathrm{mg} / \mathrm{cm}^{3}$. Variant II of knitted fabric with surface density $\mathrm{Ms}=436 \mathrm{~g} / \mathrm{m}^{2}$ and thickness $\mathrm{T}=2.6 \mathrm{~mm}$ has a bulk 
density of $167 \mathrm{mg} / \mathrm{cm}^{3}$, the bulk density of the base knitted fabric (variant i) with a surface density of $\mathrm{ms}=425 \mathrm{~g} / \mathrm{m}^{2}$ and a thickness of $\mathrm{t}=2.4 \mathrm{~mm}$ was $177 \mathrm{mg} / \mathrm{cm}^{3}$ (Fig. 2). The absolute volumetric lightness compared to the base tissue is as follows:

$$
\Delta \delta=\delta_{\mathrm{B}}-\delta=177-167=10 \mathrm{mg} / \mathrm{cm}^{3}
$$

where: $\Delta \delta$ - absolute volume lightness, $\mathrm{mg} / \mathrm{cm}^{3} ; \delta_{\mathrm{b}}-$ the bulk density of the underlying tissue $\mathrm{mg} / \mathrm{cm}^{3}$; and $\delta$ - volumetric density of experimental fabric $\mathrm{mg} / \mathrm{cm}^{3}$.

The relative ease indicators are as follows:

$$
\theta=\left(1-\delta / \delta_{\mathrm{B}}\right) \times 100=(1-167 / 177) \times 100=5.6 \%
$$

The bulk density of the basic knitted fabric with surface surface density: Ms $=402 \mathrm{~g} / \mathrm{m}^{2}$ and thickness $\mathrm{T}=2.8 \mathrm{~mm}$ in variant III is $144 \mathrm{mg} / \mathrm{cm}^{3}$., the bulk density of the base knitted fabric (variant I) is $177 \mathrm{mg} / \mathrm{cm}^{3}$.

The absolute volumetric lightness compared to the base tissue is as follows:

$$
\Delta \delta=\delta_{\sigma}-\delta=177-144=33 \mathrm{mg} / \mathrm{cm}^{3}
$$

The relative ease is as follows (Fig. 3):

$$
\theta=\left(1-\delta / \delta_{\mathrm{B}}\right) \times 100=(1-144 / 177) \times 100=18.6 \%
$$

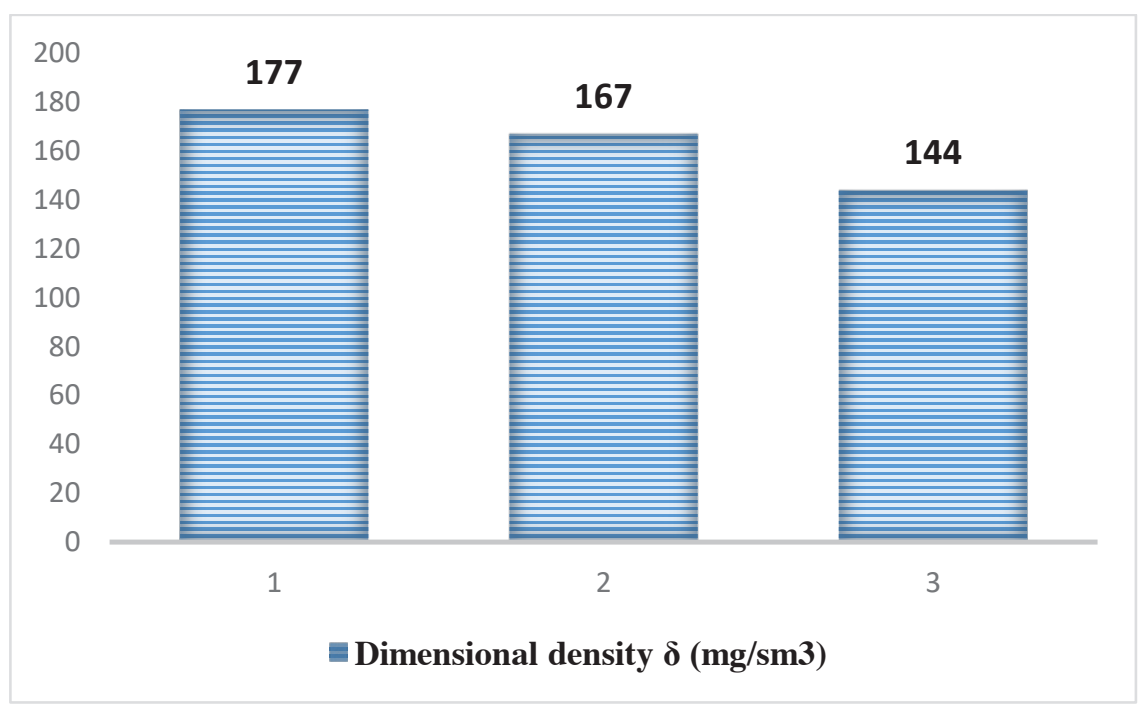

Fig. 2. Changes in the bulk density of knitted fabric

The volume density of knitwear is one of the main among the technological indicators, which shows the amount of raw material consumption in knitwear.As the surface density of knitted fabric changes, its thickness and other physical and mechanical properties change.The volumetric density of the knitted fabric varies significantly over a wide range, depending on the type and thickness of yarn used, the density of the knitting and the type of fabric and the class of machine. 


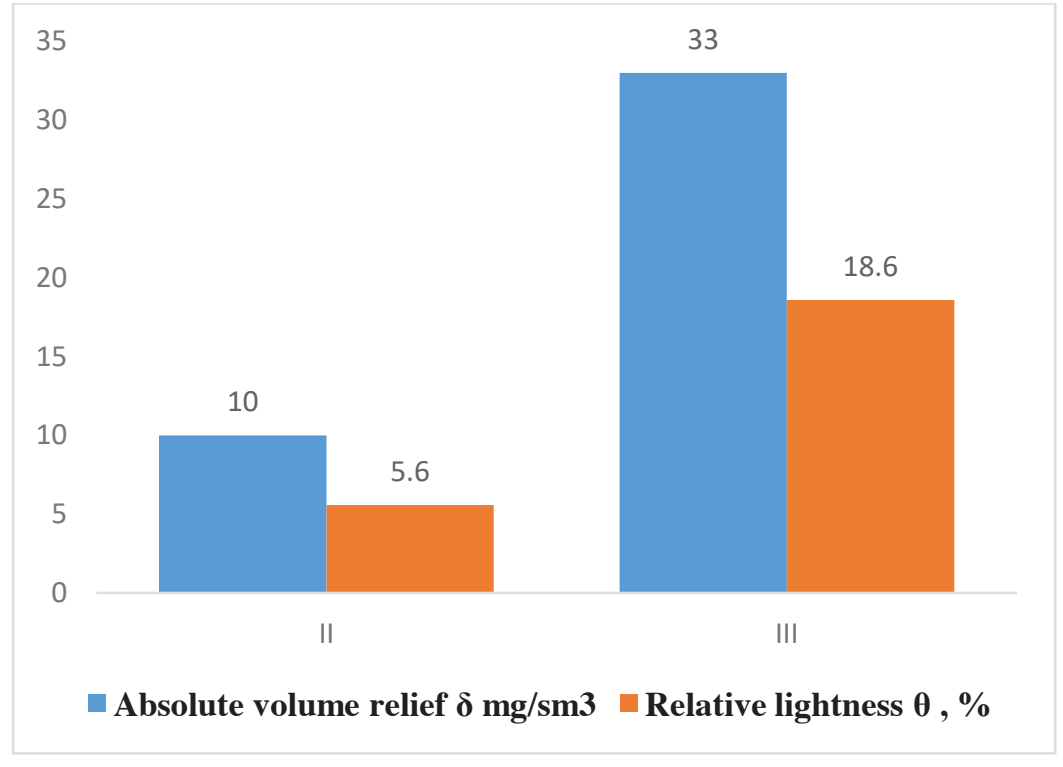

Fig. 3. Absolute volume and relative lightness of the knitted fabric

The consumption of raw materials has been reduced by changing the structure of the proposed knitted fabric. The ring step of the knitted fabric changed due to the change in the pattern report in variants II and III compared to variant I. An increase in the density of the knitwear leads to an increase in its surface density and thickness. Compared to variant I of knitting, the surface density of variant II increased by $2.5 \%$, while the surface density of variant III decreased by $5.5 \%$.

The thickness of the knitwear changes when the pattern report changes as follows: the thickness of variants II increased by $7.7 \%$ compared to variant I, and the thickness of variant III increased by $14.3 \%$. To know the raw material consumption of knitwear, we analyze its bulk density. Since the change in surface density in knitting variants II and III was less than the increase in their thickness, the bulk density of these variants was less than in version I of the knitwear. Therefore, the bulk density of variant III of knitwear is $19 \%$ less than variant I. This means that the consumption of raw materials in the production of variant III knitwear is $19 \%$ lower than in variant I. The air permeability property of woven knitted fabrics was tested on equipment YG461E based on GB/5453 (ISO 9237) standard. GB/5453 (ISO 9237) was tested under normal conditions for a pressure of $100 \mathrm{~Pa}$ and a range of $\varnothing 8.0 \mathrm{~mm}$ for ready-to-wear fabrics.

The air permeability coefficient $\mathrm{V}\left(\mathrm{cm}^{3} / \mathrm{cm}^{2} \cdot \mathrm{sec}\right)$ is determined by the following formula.

$$
B=\frac{V}{S * T}, \mathrm{~cm}^{3} / \mathrm{cm}^{2} \cdot \mathrm{sec}
$$

where: $\mathrm{V}$ - the amount of air passing through the fabric at a given pressure difference $\Delta \mathrm{P}$, $\mathrm{cm}^{3} ; \mathrm{S}$ - fabric area, $\mathrm{cm}^{2}$; and, $\mathrm{T}^{\prime}$ - the time of passage of air through the fabric, sec.

The air permeability properties of woven knitted fabrics vary from 40.4 to 43.5 $\mathrm{cm}^{3} / \mathrm{cm}^{2} \cdot \mathrm{sec}$.

The highest air permeability was observed in variant I of the knitted fabric samples and its volume was $40.4 \mathrm{~cm}^{3} / \mathrm{cm}^{2} \cdot \mathrm{sec}$ (Fig. 4). 


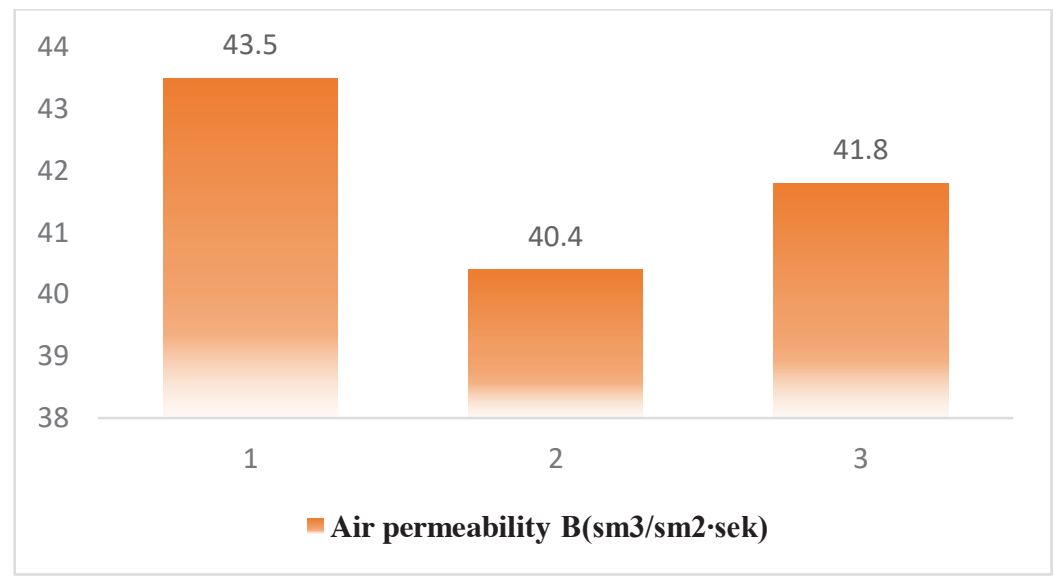

Fig. 4. Air permeability histogram of knitted fabrics

The tensile strength characteristic is an acceptable key indicator for assessing the quality of knitted fabrics. All GOST and TSH applicable to knitted fabrics include normative indicators on elongation and tensile strength. Tensile strength is the force required to break a specimen at a given size and speed. The breaking force is expressed in Newton units. The breaking strength of the submitted samples was determined using the standard method using a dynamometer YG-026T.

Fabric toughness, i.e., tensile strength analysis, showed that the most mature tissue in height 1 variant, with an index of $544 \mathrm{~N}$, was found to have a toughness of $28 \%$ higher than variant III. This is due to the fact that due to the change in the structure of the fabric, the ring pitch of the knitted fabric changed in variants II and III compared to variant I. The strength of the tissue across the width was also observed in variant I, where the tensile strength across the width of the tissue was $233 \mathrm{~N}$.

The elongation of a knitted fabric is understood as its elongation under the influence of the force expended. Elongation is characterized by the elongation of the test specimen. Elongation is expressed in absolute or relative units. When knitted fabrics with a length of $100 \mathrm{~mm}$ clamped to the tool are tested, their absolute and relative sizes are the same.

The elongation along the length of knitted knitwear ranges from $29.1 \%$ to $56.8 \%$. The highest elongation was observed in variant I of the knitted fabric, and it was $56.8 \%$ (Table, Fig. 5). The elongation of the knitted fabric variant I was found to be $48.8 \%$ higher than that of the base fabric (variant II).

The elongation of the knitted fabric in variant II was the lowest, at $29.1 \%$. The elongation across the width of the knitted fabric ranged from $49.4 \%$ to $99.55 \%$.

The maximum width elongation was observed in variant III of the knitwear and it was 99.55\%. The elongation at minimum width was observed in variant II of the knitted fabric and it was $49.4 \%$. The width elongation of variant II of knitted fabric is $26.9 \%$ less than variant III. In summary, the amount of elongation along the length and width of a knit will depend on the structure of the knitted fabric and the type of yarn it contains. When designing products, it is important to know what elastic properties knitted fabrics have [3]. 


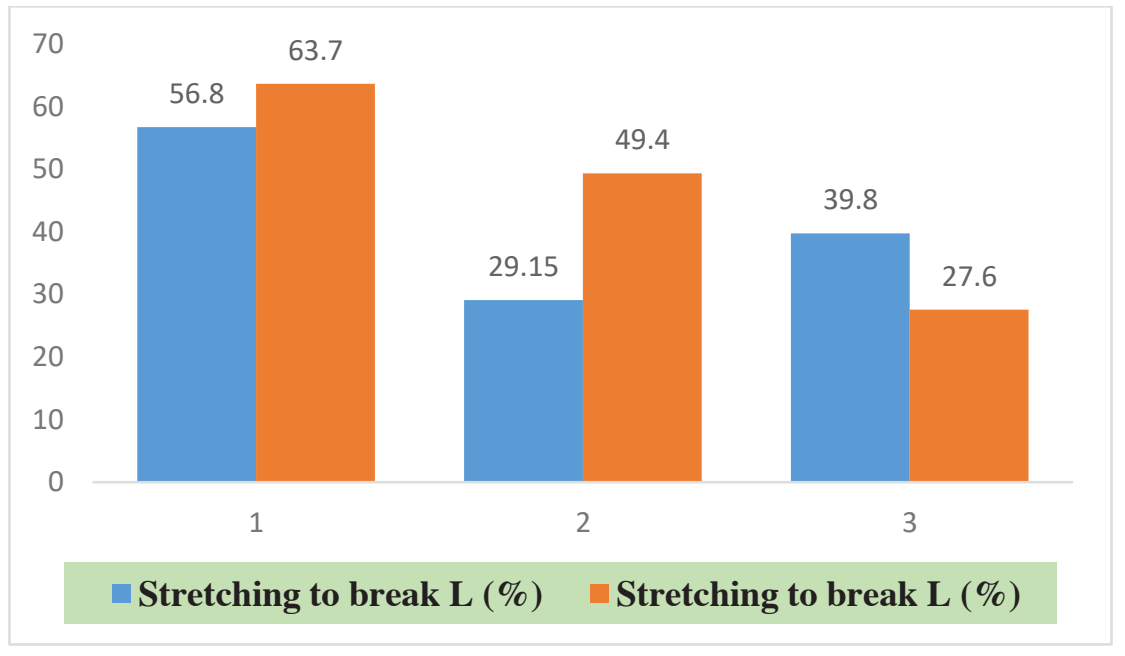

Fig. 5. Histogram of changes in the elongation of knitted tissue to rupture

The elastic portion $\varepsilon_{\mathrm{K}}$ returns at a rapid speed after the loads are withdrawn from the samples being tested; elastic deformation $\varepsilon_{\ni}$ develops at a slow rate, connected with the passage of the relaxation process; plastic deformation ep typically does not return after the loads are removed from the samples being tested.

$$
\varepsilon=\varepsilon_{\kappa}+\varepsilon_{\ni}+\varepsilon_{n}, \%
$$

The elasticity, stiffness, and amount of loops in the yarn all affect the knit's deformation. The internal, two major forces influence not only the description of the deformation, but also the condition of the knitting: the elastic force of the yarn bending into the ring tends to straighten the yarn and modify its shape. As a result, a frictional force is formed between the threads, preventing the threads from being placed in the loop and interfering with the knitted fabric's structure.

Deformation properties were determined on the model YG026A-III. Samples were prepared $30 \times 5 \mathrm{~cm}$ long and subjected to a force of $454 \mathrm{~g} \times 3(13 \mathrm{~N})$ for $30 \mathrm{~min}$. According to the results, the proportion of longitudinal deformation in knitted knitted fabric samples varies from $86.3 \%$ to $90.1 \%$, and the proportion of reverse deformation in width varies from $82.8 \%$ to $85.2 \%$. Such indicators of the proportion of back deformation indicate that the knitted fabric quickly returns to its original position after stretching. In the process of wet processing of knitted fabrics (washing, drying), the decrease in size is called penetration, and the increase is called traction.

Knitted fabrics have a far higher elongation than woven fabrics and a highly elastic structure, even when subjected to minor forces. The concept of operation of machines for finishing knitted fabrics is nearly identical to that of woven fabric finishing machines. Excessive distortion of knitted materials in finishing procedures has been identified as one of the main causes of high penetration.

The less the knit enters the processing, the better the shape-retaining characteristics of the fabric. The influence of the amount of polyacrylonitrol and polyester yarns in the composition of knitted fabrics on the elasticity has been studied. The penetration of patterned knitted fabric samples varied from $2 \%$ to $5.8 \%$ in height and from $2 \%$ to $5 \%$ in breadth, according to the findings of a research of the penetration process.

Knitted products are prone to abrasion when they come into contact with nearby objects, and as a result, some areas of the product become worthless. 
The variants with the highest abrasion resistance of the resulting knitted fabric are II and I. Variant II friction resistance 41.1 thousand months. The friction resistance of variant I is 38.3 thousand units. It was found that the friction resistance of variant III was 3.3 thousand less than that of Variant II.

\section{Conclusion}

To summarize, the above analysis of the technological and physico-mechanical properties of knitted fabrics revealed that changing the knitting report of knitted fabric structures has a positive impact on the air permeability, toughness, elongation, and abrasion resistance properties of knitted fabric. The change in tissue structure when weaving knitted fabrics from spun polyacrylonitrile yarns enables for knitted products with high sanitary and shaperetaining capabilities, hardness, and a beautiful look.

\section{References}

1. Sh. Shogofurov, I. Kamalova, Q. Xoliqov, U. Meliboev, Solid State Technology 63(6), 11798-11807 (2020)

2. A. Juraboev, Q. Kholiqov, Sh. Shog'ofurov, ACADEMICIA: An International Multidisciplinary Research Journal 10(4), 397-404 (2020)

3. K. Kholikov, A. Zhuraboev, Sh. Shogofurov, D. Abduvaliev, The Way of Science 1(71), 11 (2020)

4. K. M. Kholikov, M. M. Mukimov, Bulletin of the Scientific and Technical Institute of the Namangan Institute of Engineering Technologies 4(SI), 41-46 (2019)

5. Sh. Shogofurov, K. Kholikov, Asian Journal of Multidimensional Research 10(2), 119124 (2021)

6. Sh. Sh. Shogofurov, R. S. Umarjonovna, K. I. Ibroximovna, K. K. Madaminovich, South Asian Journal of Marketing \& Management Research 11(2), 68-73 (2021)

7. T. Allamuratova, A. Djuraev, M. Mukimov, International Journal of Advanced Research in Science, Engineering and Technology 5(10), 7178-7185 (2018)

8. T. Allamuratova, M. Mukimov, International Journal of Advanced Research in Science, Engineering and Technology 5(2), 5136-5141 (2018)

9. K. Shinsuke, The Japan Journal 11-13 (2009)

10. Sh. Kawasaki, Statistical handbook of Japan, 209 (Statistical Research and Training Institute Press, Tokyo, 2007)

11. D. Farama, A. Curteza, I. Hritcu, Polypropylene 1, 177-181 (2000)

12. B. Grazyna, S. Edward, Fibres and Text. East. Eur. 10(4), 45-48 (2002) 